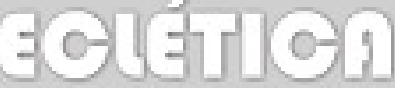 \\ quimica
}

WWW.SCIELO.BR/EQ

VOLUME 36, NÚMERO 2, 2011

\section{Determinação de amônia no ar utilizando um sensor piezelétrico de quartzo}

J.R.M. Castro, D.L. Branco, V.R. Balbo, M.F. Oliveira e J.F. Andrade Departamento de Química FFCLRP/USP - 14040-901 - Ribeirão Preto/SP-Brasil

\section{Resumo:}

Neste estudo, procurou-se desenvolver e avaliar filmes para a captação e quantificação de vapores de amônia no ar, através de um sensor piezelétrico de quartzo. Muitas substâncias e suas misturas, em diferentes proporções, foram investigadas como possíveis filmes captores. Em etapas seguintes, verificaram-se alguns parâmetros importantes como o efeito da vazão do poluente, da temperatura de trabalho e da massa da película, otimizando-se as condições experimentais para a montagem do método. Concluiu-se que o filme mais promissor, sob as condições ajustadas, seria uma mistura 2:1 (v/v) de solução comercial (A) de ácido glicólico (70 \% $\mathrm{m} / \mathrm{m}$ ) em água, adicionada a tetrakis(hidroxietil)etilenodiamina - THEED (3:4 v/v), com uma solução saturada (B) de ácido tânico em acetona. Estudos de repetibilidade, do tempo de contacto (poluente-sensor) e de alguns possíveis interferentes completaram os trabalhos. As curvas analíticas resultantes mostraram faixas lineares na região de trabalho $(2,0$ a $11 \mathrm{ppm}_{\mathrm{v}}$ ou 1,4 a $7,7 \mathrm{mg} / \mathrm{m}^{3}$ de $\mathrm{NH}_{3}$ ), para quatro diferentes tempos de exposição $(0,5 ; 1 ; 2$ e $3 \mathrm{~min})$, com coeficientes de correlação (r) variando 
entre 0,9994 e 0,9980, e respectivas sensibilidades de 13,5 a $42,0 \mathrm{~Hz} /$ $\mathrm{ppm}_{\mathrm{v}}$.

Palavras-chave: amônia, sensor piezelétrico (MCQ), ácido glicólicoácido tânico-THEED filme.

\section{Introd ução}

\section{Amônia}

A amônia é um gás incolor à temperatura ambiente, possui um odor muito forte e é consideravelmente mais leve que o ar. Possui ponto de fusão de $77,7^{\circ} \mathrm{C}$, e ponto de ebulição de $-33,4^{\circ} \mathrm{C}$, sendo bastante solúvel em água e podendo ser removida sob fervura [1]. No estado líquido, comercialmente disponível em solução aquosa de $15 \mathrm{~mol} \mathrm{~L}^{-1}(28 \% \mathrm{~m} / \mathrm{v})$, com a denominação de amoníaco, a amônia é um dos solventes que mais tem sido usado para o estudo de reações químicas. Além disso, a amônia pode formar misturas explosivas com o ar, à temperatura e pressão ambiente, quando presente em concentrações de 16-27\% em volume. Os produtos da combustão são, principalmente, nitrogênio e água, com traços de nitrato de amônio e dióxido de nitrogênio [2].

Produzida industrialmente, geralmente, pelo processo de HaberBosch, que combina diretamente $\mathrm{N}_{2}$ e $\mathrm{H}_{2}$, usando ferro como catalisador misturado com alguns óxidos $\left(\mathrm{Al}_{2} \mathrm{O}_{3}, \mathrm{~K}_{2} \mathrm{O}, \mathrm{SiO}_{2}, \mathrm{CaO}, \mathrm{MgO}\right)$, a $450^{\circ} \mathrm{C}$ e 270 atm de pressão[3], a amônia é utilizada em grande quantidades no mundo todo devido às suas diversas propriedades. Dentre essas aplicações, destacam-se o seu uso como fonte de nitrogênio na fabricação de fertilizantes, na forma de sais de amônio (nitrato, fosfato, sulfato) ou uréia; como agente neutralizador na indústria do petróleo e gás de refrigeração em sistemas industriais, pois seu alto poder refrigerante e baixo potencial de destruição do ozônio estratosférico tornam este gás 
adequado para ser usado em grandes máquinas de refrigeração industrial, evitando assim os usuais compostos clorofluorcarbonetos $\left(\mathrm{CFC}_{\mathrm{s}}\right)[\mathbf{1 , 4}]$.

Em ambientes fechados, o grande problema da amônia é o vazamento nos sistemas de refrigeração representando, assim, um risco à saúde das pessoas que trabalham nestes locais. Uma pessoa pode ser exposta diariamente a $30 \mathrm{ppm}_{\mathrm{v}}$ de amônia durante 8 horas de trabalho, sendo o limite olfativo médio do ser humano em torno de $55 \mathrm{ppm}_{\mathrm{v}}$. Apenas algumas dezenas de ppm deste gás são necessárias para produzir um odor extremamente desagradável. Porém, com a perda de sensibilidade específica do olfato, após algum tempo de permanência em ambientes contaminados por amônia, são imprescindíveis a disponibilização de sistemas de detecção química fáceis de operar, de baixo custo e resposta rápida, capazes não apenas de detectar, mas, também, quantificar os níveis deste gás em uma ampla faixa de concentrações. Outro problema que ocorre em ambientes fechados está relacionado com a criação extensiva de animais, que é usualmente feita confinando-os em um determinado espaço. Como as fezes e urina são fontes de amônia, isso pode resultar em concentrações locais elevadas do composto, o que vai interferir na saúde dos animais, podendo ocasionar prejuízo aos produtores. Neste caso, métodos analíticos que forneçam dados sobre a concentração média diária de amônia ajudariam a controlar esses problemas [1].

A amônia pode ser determinada utilizando-se várias técnicas, tais como pontenciometria [5], injeção em fluxo [6], amostragem difusiva [7], dentre outras mais. Contudo, as metodologias empregadas envolvem etapas complicadas, além de exigirem alguns pré-tratamentos. Na literatura, encontram-se alguns trabalhos mais recentes sobre a determinação de amônia, através de sensores piezelétricos [8-10], os quais, mais especificamente, empregam a microbalança de cristal de quartzo (QCM), que seria uma alternativa mais barata, rápida e prática, em relação às demais técnicas citadas anteriormente. 
Fundamentos da técnica e pequeno histórico

O sensor piezelétrico de cristal de quartzo ou microbalança de cristal de quartzo (quartz crystal microbalance - QCM) é um dispositivo especialmente interessante e instrutivo. Este sensor está baseado nas características piezelétricas do quartzo que, estando conectado a um circuito elétrico apropriado, oscila a uma frequência constante e característica da sua massa e forma. Esta propriedade, compartilhada também por outros materiais cristalinos, é chamada de efeito piezelétrico, sobre a qual se fundamenta a microbalança de cristal de quartzo. A frequência constante, característica do cristal (diapasão) constitui a base do controle de tempo dos relógios e cronômetros modernos de alta precisão, controle de aparelhos de GPS, filtros da maioria dos equipamentos eletrônicos, contadores e frequencímetros, propriedades essas que levaram a muitos outros sistemas instrumentais analíticos mais exatos e precisos [11].

Quando uma pequena massa de material é depositada sobre a superfície de um cristal de quartzo oscilante, a sua frequência de vibração diminui. Essa variação de frequência, $\Delta \boldsymbol{F}(\boldsymbol{H} z)$, tem uma relação linear com a massa incorporada à face da lâmina cristalina que, de acordo com Sauerbrey [12], para cristais com corte AT, é dada pela equação: $\Delta \boldsymbol{F}=\mathbf{- 2 , 3 \times 1 0 ^ { 6 }}$ $\boldsymbol{F}_{0}{ }^{2}(\Delta \boldsymbol{M} / \boldsymbol{A})$; sendo $\Delta \boldsymbol{F}(\boldsymbol{H} z)$ a diminuição da frequência oscilante causada pela película metálica (eletrodo) ou filme (coating) depositado, $\boldsymbol{F}_{\boldsymbol{0}}(\boldsymbol{M H z})$ a frequência ressonante fundamental da lâmina de cristal de quartzo, $\Delta \boldsymbol{M}(\boldsymbol{g})$ a massa total depositada em ambas as faces do cristal e $\boldsymbol{A}\left(\boldsymbol{c m}^{2}\right)$ a área ativa do eletrodo de uma de suas faces [13].

Desta maneira, obtém-se uma microbalança aplicando-se sobre a superfície do eletrodo/cristal uma fina película (filme, "coating”), também chamada de substrato captor, que geralmente é um polímero estável que tenha afinidade pela substância gasosa/poluente que se deseja detectar e quantificar. Na prática, faz-se passar um fluxo controlado do 
gás de arraste, contendo o analito de interesse, simultaneamente, sobre ambos os lados do cristal de quartzo. Sendo o poluente captado por sorção, através do filme específico, causará uma diminuição da frequência de vibração do sensor, cujo valor está relacionado à massa ou à concentração desse analito.

Esses sensores têm sido usados para detectar uma variedade de substâncias em fase gasosa. Acham-se descritos métodos para amônia, acetoína, sulfeto de hidrogênio, dióxido de enxofre, ácido clorídrico, dióxido de nitrogênio, mononitrotolueno (explosivo), metilaminas, vapores de mercúrio, hidrogênio, ácido cianídrico, monóxido de carbono, dióxido de carbono, formaldeído, fosgênio, ozônio, tolueno, xileno e outros hidrocarbonetos aromáticos, diisocianato de tolueno, dinitrato de propileno glicol, gases anestésicos (hidrocarbonetos halogenados), compostos organofosforados e defensivos agrícolas [14].

As aplicações analíticas dos cristais piezelétricos "recobertos" começaram a partir de 1964, quando King [15-17], trabalhando com substâncias usadas como fases estacionárias em cromatografia, recobriu os eletrodos com tais substratos detectando e quantificando os afluentes gasosos. Utilizando a equação de Sauerbrey, King estimou em 1 ng o limite teórico de detecção, batizando o dispositivo de "detector piezelétrico de sorção". Devido à sua elevada sensibilidade, baixo custo, pequeno tamanho, seletividade e robustez, tal detector revelou-se ideal para muitos propósitos analíticos, mostrando-se especialmente aplicável em baixas temperaturas, tornando possível a análise de compostos normalmente instáveis acima da temperatura ambiente. Recobrindo os cristais com peneiras moleculares, polímeros higroscópicos, sílica gel e líquidos polares, King desenvolveu e comercializou o primeiro detector de umidade capaz de acusar 0,1 ppm $_{\mathrm{v}}$ de vapor de água no ar, tendo também trabalhado com hidrocarbonetos (xileno).

Sem dúvida, para o desenvolvimento de novos métodos analíticos, na década de setenta, Guilbault \& colaboradores [14,18-29] deram uma 
grande contribuição, principalmente, no estudo de vários poluentes gasosos. Ao longo dos anos, pesquisas intensas foram realizadas e conduziram ao desenvolvimento de muitos detectores de fase gasosa para vapores orgânicos, poluentes ambientais e detectores cromatográficos.

Segundo O'Sullivan \& Guilbault [18] o primeiro imunossensor de fase gasosa foi descrito por Guilbault \& Ngeh-Ngwainbi (1988), sendo que também, nesse mesmo ano, Fawcett et al. foram os primeiros a descrever um biossensor para DNA. Esta área tem chamado muito a atenção dos pesquisadores, pois o uso de anticorpos atuando como revestimento dos eletrodos oferece uma específica biosseletividade ao método.

Para a detecção de gás de amônia existem estudos recentes de diferentes filmes que aumentariam a sensibilidade e eficiência do método analítico, tais como: filmes de polivinilpirrolidona (PVP), que servem também para determinar aminas alifáticas [10]; filmes nanoporosos de polieletrólitos com uma camada de $\alpha-Z r P$ depositados sobre as faces dos eletrodos, pelo método "Layer by Layer", sendo a função dos polieletrólitos estabilizar a estrutura porosa do filme, além de manter a sua umidade relativa, o que aumentaria a sensibilidade do filme para a amônia e outros gases hidrofílicos [30]; filmes de $\mathrm{Ta}_{2} \mathrm{O}_{5}[\mathbf{3 1}]$, filmes de $\mathrm{ZnO}[32]$ entre outros.

\section{Materiais e métodos}

\section{Aparelhagem e arranjo experimental}

Neste trabalho foram utilizados cristais piezelétricos de quartzo de $10 \mathrm{MHz}$, com corte AT (mais estáveis e com baixo coeficiente de temperatura entre 10 e $50^{\circ} \mathrm{C}$ ), não-polidos, contendo finíssimos depósitos de ouro (eletrodos) em ambos os lados, disponíveis comercialmente e montados em suportes de cerâmica modelo HC-6/U (ICM, Oklahoma, OK, USA). O diâmetro do disco laminar de quartzo geralmente é de 10 a 16 
$\mathrm{mm}$, com aproximadamente $0,15 \mathrm{~mm}$ de espessura, sendo que o eletrodo metálico tem espessura entre 3.000 e $10.000 \AA$ e diâmetros variando de 6 a $8 \mathrm{~mm}$ (área superficial ativa acerca de $0,40 \mathrm{~cm}^{2}$ ).

O cristal, após ser recoberto com o filme adequado, foi colocado em uma célula de vidro, ficando suas faces expostas ao fluxo de vapores, e ligado a um oscilador transistorizado OT-13 (ICM, Oklahoma), que o manteve vibrando em sua frequência ressonante. O oscilador é alimentado por uma fonte reguladora de voltagem (Heathkit, modelo IP - 2728) ajustada para aplicar 9 volts dc, e a frequência de saída foi monitorizada por um frequencímetro digital (Goldstar FC2015), com sensibilidade de $\pm 1,0 \mathrm{~Hz}$ (8 dígitos), em intervalos de tempo cronometrados. Esse arranjo experimental seguiu um diagrama de blocos (Fig.1) já utilizado em trabalhos anteriores sobre estudo de poluentes gasosos [14], sendo, a maioria das etapas, realizada sob temperatura ambiente $\left(25^{\circ} \mathrm{C}\right)$.

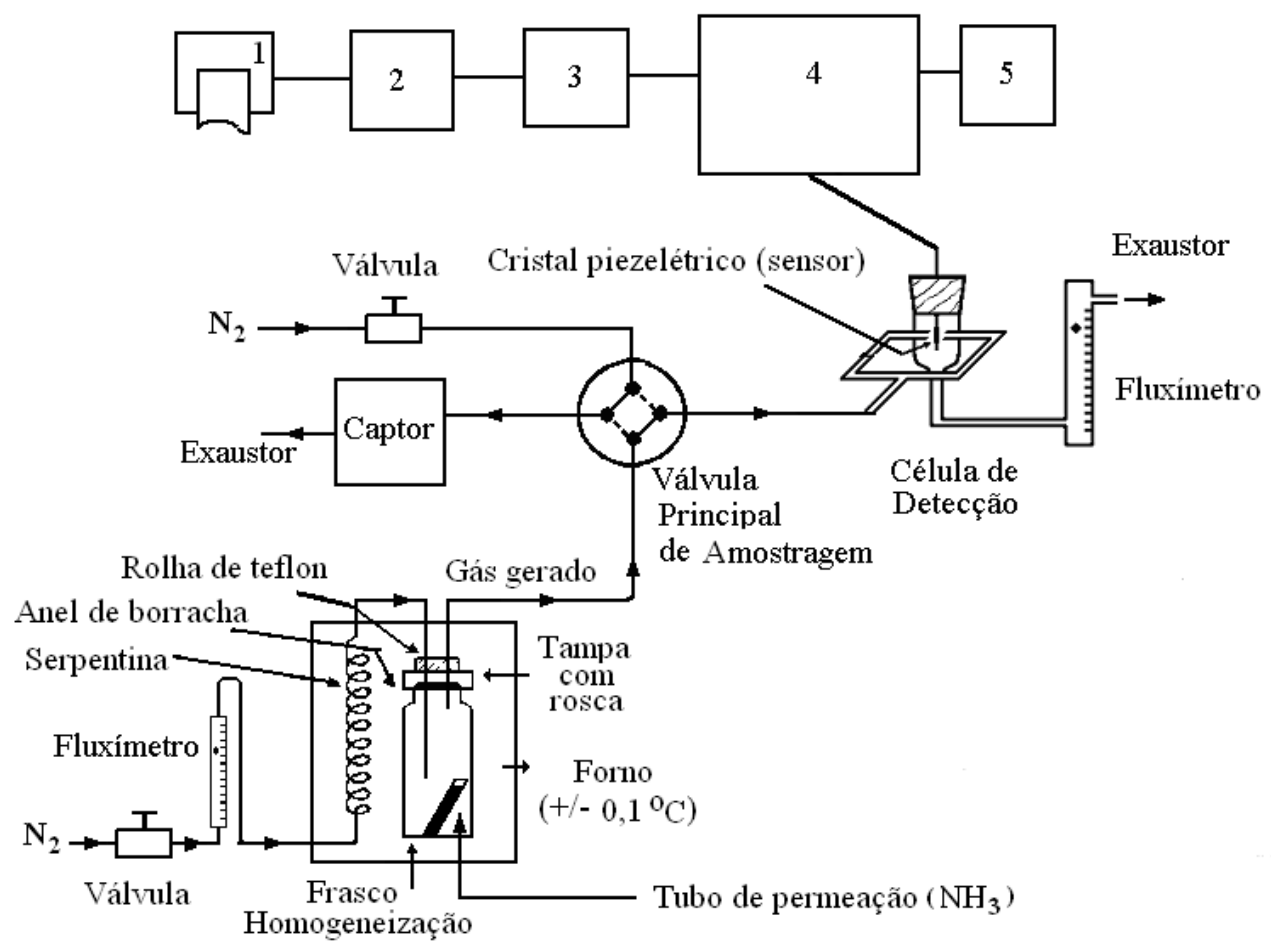

Figura 1. Arranjo experimental completo utilizado. 
1) Registrador; 2) Conversor digital-analógico;

3 ) Frequencímetro; 4) Oscilador e 5) Fonte/voltagem.

Para se aumentar a praticidade do sistema, conectou-se na entrada da célula uma válvula principal de aço inoxidável com duas posições em 90 graus (Varian), e quatro orifícios (duas entradas e duas saídas), que permitem alternar o fluxo de entrada na célula detectora entre o gás de arraste puro $\left(\mathrm{N}_{2}\right.$ ou ar seco), e a amostra do poluente gasoso $\left(\mathrm{NH}_{3}\right)$ devidamente diluído. Para se monitorar as vazões dos gases de arraste e da amostra ao longo da linha, usam-se fluxômetros calibrados (Matheson e Cole-Parmer) pelo método dos "pistões sem atrito", utilizando os chamados medidores de bolha de sabão, conforme a literatura [33, 34]. As tubulações foram feitas com mangueiras de Tygon e pequenas conexões de vidro ou plástico (Nalgene). Algumas válvulas de agulhas (inox ou latão), secundárias, foram necessárias para ajustar os fluxos de trabalho na maioria das configurações experimentais.

$\mathrm{Na}$ prática, primeiro se passa o gás de arraste puro pelo sensor piezelétrico de quartzo até que ele vibre numa frequência base constante. Então, aciona-se a segunda posição da válvula principal (entrada) para que a amostra do poluente entre na célula detectora, iniciando a interação entre a amostra gasosa e o filme sobre o cristal, que resulta na sorção/captação da substância de interesse. Depois de certo tempo controlado de exposição, a nova frequência de vibração é registrada. Se a queda da oscilação atinge um valor constante, geralmente após longo tempo de exposição, significa que o equilíbrio pode ter sido alcançado (saturação do filme). Reposicionando-se a válvula principal novamente para o fluxo de nitrogênio na célula, geralmente observa-se uma dessorção completa do poluente, com o cristal retornando à sua frequência base e, dessa maneira, o sensor está pronto para ser usado novamente. Em alguns casos, essa desejável regeneração do filme pode não ser completa, mas 
isso também não inviabilizaria o método, desde que as respostas (quedas de sinais) continuem sendo proporcionais às concentrações do analito.

Preparo e aplicação dos filmes (coatings)

Foram utilizados solventes voláteis (Etanol, Acetona, Clorofórmio J.T.Baker) para dissolver a substância, ou a mistura de substâncias, que constituem os diferentes filmes avaliados. O cristal de quartzo foi coberto por cada película pela técnica do espalhamento da gota, na qual a solução é transferida para o centro dos eletrodos de ouro, a partir de uma gota, que é espalhada pelas suas superfícies. Depois o cristal é colocado numa estufa a 60-70 ${ }^{\circ} \mathrm{C}$ para que o solvente se evapore completamente, deixando uma película uniforme do substrato captor distribuído sobre ambas as superfícies metálicas. Todo material sorvido (analito) fica apenas sobre as áreas dos eletrodos, sendo tal acréscimo de massa monitorado pela diminuição da frequência de oscilação do cristal e calculado pela equação de Sauerbrey [12].

\section{Geração de gases e vapores padronizados}

As amostras necessárias, com concentrações exatas do analito, geralmente são geradas de forma contínua pela constante inserção do poluente produzido ao fluxo principal do gás de arraste. A geração ocorre de forma controlada, através de um tubo de permeação artesanal [35], comercial ou ainda em processo semelhante por difusão capilar. O gás de arraste usado foi nitrogênio, sob vazão e temperatura controladas através de um sistema de calibração (Precision Gás Standards Generator, modelo 570C, Kin-Tek Laboratories, Texas City). Esses métodos dinâmicos de geração de gases e vapores padronizados têm a vantagem de não ser limitado pelo volume da mistura gasosa, sendo também as perdas por interação com as superfícies praticamente eliminadas pelo fluxo contínuo, o que conduz o sistema a um estado estacionário. O grau de confiança na exatidão desses métodos depende, principalmente, da exatidão com que o fluxo do gás diluente é 
medido e da exatidão das medidas da quantidade de contaminante que é disperso continuamente no diluente.

A geração de gases padronizados através de um tubo de permeação está fundamentada no fenômeno apresentado por algumas espécies químicas que, quando fechadas em um tubo de plástico inerte, escapam por dissolução e permeação, através de membranas plásticas, com velocidade de permeação obedecendo à lei de Fick. Com isso, a velocidade de permeação pode ser expressa por equações que derivam da seguinte: $R=$ $D S\left(P_{1}-P_{2}\right) A / L$ [36] ; sendo $R$ a velocidade de permeação, $A$ a área superficial da membrana, $D$ o coeficiente de difusão, $L$ a espessura da membrana, $S$ a constante de solubilidade, $P_{1}$ e $P_{2}$ as pressões parciais em cada lada da membrana.

O'Keeffe \& Ortman [37] foram os primeiros a relatar o uso de um tubo de permeação para a produção de misturas gasosas padronizadas. A concentração padrão do analito gerado pode ser calculada pela equação: $C_{p p m}=R .22,4.10^{6} \mathrm{~T} 760 \mathrm{mmHg} /(F M 273 P)$; sendo: $\mathrm{C}_{\mathrm{ppm}}$ a concentração do vapor, $\mathrm{R}\left(\mathrm{ng} \mathrm{min}^{-1}\right)$ a razão de permeação específica do tubo, F (mL $\left.\min ^{-1}\right)$ a vazão do gás de arraste, $M\left(\mathrm{~g} \mathrm{~mol}^{-1}\right)$ a massa molar do material permeante, T (K) a temperatura e P (mmHg) a pressão do sistema. Com esta equação, consegue-se calcular as concentrações padrões geradas do poluente, para diferentes vazões do gás de arraste, a uma determinada temperatura [38]. Para gerar amônia, nos estudos preliminares deste trabalho, usou-se difusão capilar em dispositivo de vidro contendo hidróxido de amônio. Uma vez definido o melhor filme, o restante do trabalho foi todo conduzido com amônia gasosa gerada por permeação de amônia líquida (Fig.1).

\section{Resultados e Discussão}

Estudo de possíveis filmes (captores) para amônia 
Na tabela 1 acham-se listadas as principais substâncias, e algumas de suas combinações, que foram testadas inicialmente como possíveis filmes para recobrir o cristal de quartzo. Para isso cada solução foi aplicada à superfície do eletrodo, secada em estufa, colocada na célula, ficando exposta ao fluxo de gás de arraste puro, e depois com poluente, sempre sob uma mesma vazão $(80 \mathrm{~mL} / \mathrm{min})$, temperatura $\left(25^{\circ} \mathrm{C}\right)$ e concentração de amônia $\left(\sim 20 \mathrm{ppm}_{\mathrm{v}}\right)$. Dessa forma, verificaram-se aqueles substratos que apresentavam alguma interação com a amônia, ou seja, uma queda significativa da frequência do cristal, em curto tempo de contacto poluente-captor.

Tabela 1. Principais substâncias e suas misturas testadas como filmes

\section{Substrato Captor (individual ou mistura)}

Porfirina

$\mathrm{N}, \mathrm{N}$ - dimetilestearamida

THEED* + porfirina + cloridrato de piridoxina $1: 1: 1$

Carbowax $400+$ cloridrato de piridoxina

Carbowax 400

Carbowax $400+$ ácido dipicolínico $1: 1$

Carbowax + zeólita H-ZSM-5 $1: 1$

Poliol $442+$ Eritromicina $1: 1$

Tween $80+$ eritromicina + cloridrato de piridoxina

Tween $80+$ Nipic $^{* *}$ $1: 1$

Tween $80+$ Nipic + cloridrato de piridoxina $1: 1: 1$

Tween 80 + cloridrato de piridoxina + ácido linolênico

THEED + cloridrato de piridoxina + Nipic $1: 1: 1$

THEED + cloridrato de piridoxina + ácido linolênico Várias

Ácido linolênico + cloridrato de piridoxina

Várias

Tween $80+$ cloridrato de piridoxina + EDTA $1: 1: 1$

Tween 80 + cloridrato de piridoxina + ácido linolênico $10: 10: 1$ 
Tween $80+$ cloridrato de piridoxina + Nipic

Tween 80 + cloridrato de piridoxina + porfirina

Tween $80+$ porfirina

Tween 80 + cloridrato de piridoxina + ácido picolínico

Tween 80 + THEED + cloridrato de piridoxina

Várias

Tween 80 + cloridrato de piridoxina + poliol 442

Várias

THEED + cloridrato de piridoxina + poliol 442

$1: 1: 1$

Poliol 442 + ácido linolênico

Tween $80+$ cloridrato de piridoxina + glicerina

Triton X-100*** + tween 80 + cloridrato de piridoxina

THEED + cloridrato de piridoxina

Tween $80+$ sacarose

Tween 80 + zeólita H-ZSM-5

Tween $80+$ cloridrato de piridoxina + diglicina

Tween 80 + ácido kójico

Tween 80 + cloridrato de piridoxina + ácido kójico

Várias

Tween 80 + cloridrato de piridoxina + ácido kójico + ácido linolênico 5:5:5:1

Acetato de celulose + ácido linolênico

Várias

THEED + ácido linolênico

Ácido linolênico + ácido kójico + acetato de celulose

Polibutadieno + Nipic

Acetato de celulose + Nipic + cloridrato de piridoxina + ácido kójico 1:1:1:1

Ácido linolênico + Nipic + ácido kójico + cloridrato de piridoxina

Ácido linolênico + cloridrato de piridoxina + ácido kójico

Ácido kójico

Cloridrato de piridoxina + ácido kójico

Tween $80+$ cloridrato de piridoxina + Nipic

Ácido glicólico

Ácido glicólico + ácido linolênico

Tween 80 + ácido glicólico

Ácido glicólico + Nipic 
THEED + ácido glicólico

Várias

THEED + ácido glicólico + ácido tânico

Várias

Ácido glicólico (fundido sobre o cristal)

Tween 80 (puro) + ácido glicólico

$1: 1$

Tween 80 + cloridrato de piridoxina + ácido glicólico

$1: 1: 1$

continua

Glicina

Glicina + ácido glicólico

Glicerina

Ácido glicólico + ácido kójico

Várias

Ácido oxálico

Ácido glicirrhízico

Ácido glicirrhízico + cloridrato de piridoxina

THEED + ácido glicirrhízico

Ácido glicirrhízico + porfirina

Ácido glicirrhízico + ácido kójico

Ácido glicirrhízico + Nipic

UCON LB - 550X + ácido glicirrhízico

UCON LB - 550X + ácido glicirrhízico + ácido glicólico

2,4-pentanodiol

Poliol 471

Poliol 471 + ácido glicólico

Tween 80 + ácido glicirrhízico

Ácido glicirrhízico + ácido glicólico

$5: 1$

Poliol $442+$ ácido glicirrhízico

$1: 1$

Didecylphtalate

Ácido ascórbico + ácido glicirrhízico

Ácido amino-n-butírico

Ácido salicílico

THEED + ácido salicílico

$\beta$-ciclodextrina

Tween 80 + glicerina + ácido glicólico + acetato de celulose 
Tween 80 + glicerina + ácido glicólico

$1: 1: 1$

Acetato de celulose + ácido glicólico

$1: 1$

Tween $80+$ cloridrato de piridoxina + Nipic $+\beta$-ciclodextrina

Tween $80+$ cloridrato de piridoxina $+\beta$-ciclodextrina

$1: 4: 4$

Ácido glicirrhízico + Nipic

$1: 1$

Etilenoglicol

Etilenoglicol + ácido glicólico

Azul de bromofenol

Tween 80 + ácido glicólico + uréia

Tergitol NPX

N,N-dimetilestearamida + ácido glicólico

Dietilenoglicol

Dietilenoglicol + ácido glicólico

$1: 1$

Tetraetilenoglicol dimetil éter + ácido glicólico

$1: 1$

THEED + tetraetilenoglicol dimetil éter + ácido glicólico

Alltech AT 220 ou (amina 220)

Alltech HI-EFF-1BP

Ácido glicólico + Alltech HI-EFF-1BP

THEED + ácido glicólico + Alltech HI-EFF-1BP

THEED + Alltech HI-EFF-1BP

Ácido glicólico + ácido linolênico

$1: 1$

Ácido glicólico + Alltech HI-EFF-1BP

$1: 1$

THEED + Alltech AT 220

$1: 1$

THEED + floroglucina

$1: 4$

Ácido mandélico

THEED + ácido mandélico

Tween 80 + ácido mandélico

$1: 1$

*THEED = Tetrahidroxyethylethylenediamine.

** Nipic $=$ Complexo de níquel com tiocianato e picolina.

*** Triton $\mathrm{X}-\mathbf{1 0 0}=$ surfactante não iônico. 
De todos os substratos testados na fase preliminar, as combinações de acetato de celulose com ácido linolênico (1:1) e THEED com ácido glicólico (1:3) foram as que apresentaram resultados mais promissores. O primeiro forneceu uma variação média de frequência de $700 \mathrm{~Hz}$, para um tempo de exposição ao poluente de 1 minuto. O THEED com ácido glicólico apresentou uma diminuição de frequência média de $1000 \mathrm{~Hz}$, porém para um tempo de exposição maior (10 minutos). Embora essas misturas forneçam uma queda de frequência interessante, nenhuma delas mostrou interação reversível, ou seja, a amônia se liga firmemente ao filme, não sofrendo dessorção quando o fluxo do gás de arraste puro é reaberto. É sempre desejável que as interações entre poluente-substrato sejam totalmente reversíveis, permitindo medidas consecutivas. Porém, sendo a preparação de novos cristais (aplicação e secagem do filme) e suas trocas bem rápidas, como também grande a sensibilidade (sinal analítico), o fato do processo ser irreversível ou parcialmente reversível não invalida o uso destes filmes para montagem de novo método analítico. Em sondagens posteriores, constatou-se ainda que a mistura THEED ácido glicólico torna-se mais eficiente, quando envelhecida (dois ou três dias) e colocada em presença de ácido tânico saturado em acetona.

\section{Estudo da melhor proporção entre os constituintes da película}

Os resultados da tabela 2 mostram a importância de se determinar a proporção ideal entre as substâncias que compõe o filme, objetivando-se a maior sensibilidade. Para cada razão testada, mantiveram-se constantes os demais parâmetros: vazão de trabalho, tempo de contacto/exposição película-poluente, temperatura e concentração de amônia, mesmo que ainda não otimizados.

A mistura de $50 \mu \mathrm{L}$ da solução (A) de ácido glicólico-THEED (3:4 v/v) com $25 \mu \mathrm{L}$ da solução saturada (B) de ácido tânico (em acetona), portanto 2:1 v/v, foi a que apresentou a melhor resposta à amônia, tendo sido escolhida e fixada como razão ideal para os estudos seguintes. 
Tabela 2. Estudo da melhor proporção entre os constituintes do filme mais promissor

\begin{tabular}{|c|c|c|}
\hline \multirow{2}{*}{$\begin{array}{l}\text { Solução de ácido } \\
\text { glicólico em THEED } \\
(3: 4 \mathrm{v} / \mathrm{v}) / \mu \mathrm{L}\end{array}$} & \multirow{2}{*}{$\begin{array}{l}\text { Solução saturada de ácido tânico } \\
\text { em acetona / } \mu \mathrm{L}\end{array}$} & $\begin{array}{l}\text { Variação de } \\
\text { frequência } \Delta F \text { / Hz }\end{array}$ \\
\hline & & $\begin{array}{l}\text { Após } 3 \quad \mathrm{~min} \\
\text { contacto }\end{array}$ \\
\hline 50,00 & 5,00 & 395 \\
\hline 50,00 & 12,50 & 430 \\
\hline 50,00 & 20,00 & 400 \\
\hline 50,00 & 25,00 & 533 \\
\hline 50,00 & 45,00 & 476 \\
\hline 50,00 & 50,00 & 451 \\
\hline ------ & $100 \%$ & 149 \\
\hline
\end{tabular}

Estudo sobre o efeito da vazão de trabalho

Um aumento na vazão de trabalho (Fig.2) geralmente provoca um acréscimo do sinal analítico, passando por um valor máximo, seguido depois por uma perda de sensibilidade na interação poluente-captor. Para o intervalo de valores de vazão verificado neste estudo, observou-se apenas um aumento contínuo, sendo que o valor ideal de vazão pôde ser estabelecido na ordem de $100 \mathrm{~mL} \mathrm{~min}^{-1}$. 


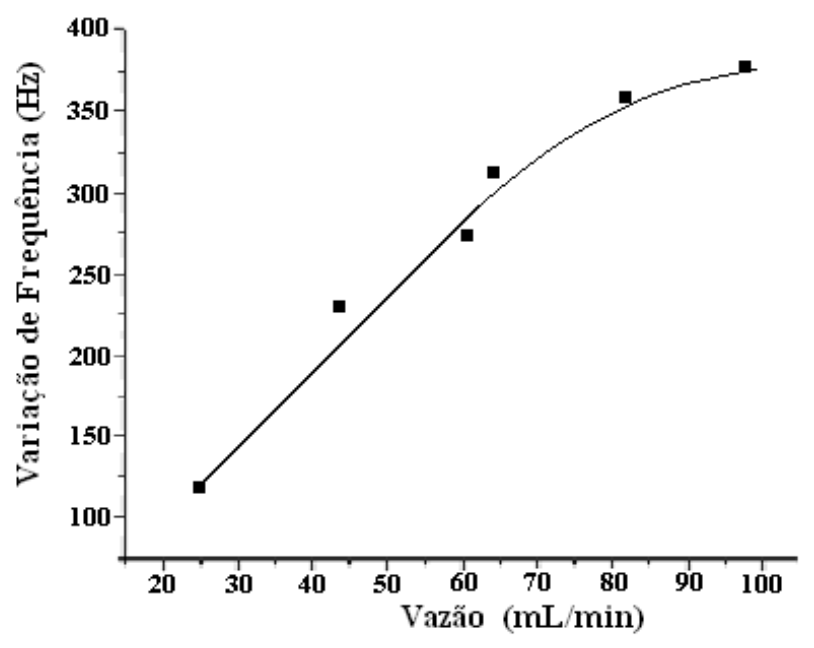

Figura 2. Efeito da vazão na célula de trabalho sobre o sinal do sensor: Tempo de interação poluente/filme $=3,0 \mathrm{~min} ., \mathrm{C}_{\mathrm{amônia}}=6,0 \mathrm{ppm}_{\mathrm{v}}, 25^{\circ} \mathrm{C}$. Valores médios de três medidas.

Estudo do efeito da massa da película sobre o cristal

$\mathrm{Na}$ (Fig.3) observa-se que o aumento da espessura do filme captor, colocado sobre o cristal, provoca também uma variação inicial positiva do sinal analítico. Porém, existe um valor máximo limite, que neste caso está em torno de $130 \mu \mathrm{g}$ da película. Quantidades acima deste valor resultam em decréscimo abrupto da sensibilidade devido, provavelmente, a impedimentos provocados pela própria estrutura do filme, uma vez que o aumento da massa depositada altera a morfologia da película, provavelmente impedindo que as moléculas de amônia alcancem os sítios ativos mais internos. 


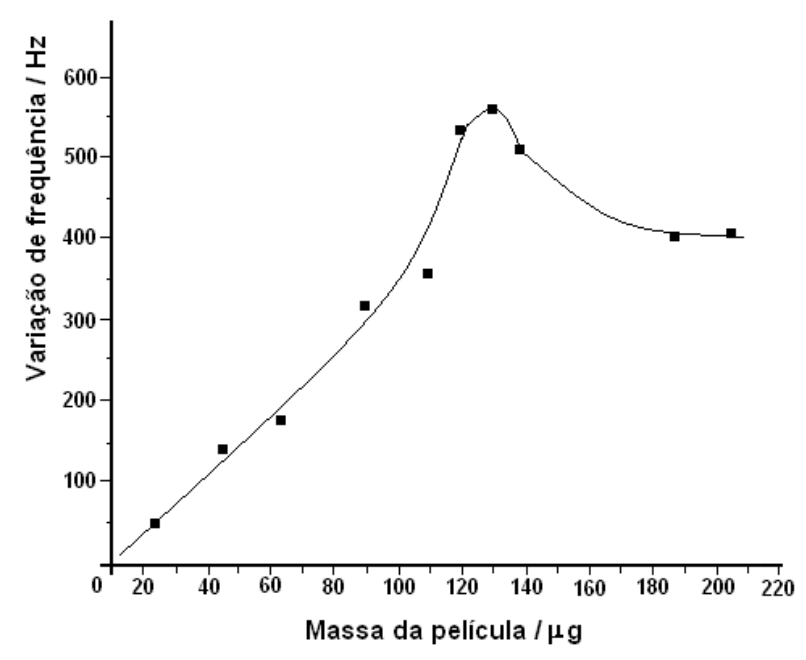

Figura 3. Sensibilidade versus massa do filme captor:Vazão: $80 \mathrm{~mL} / \mathrm{min}$, $\mathrm{C}_{\mathrm{amônia}}=6,0 \mathrm{ppm}_{\mathrm{v}}$, tempo de contacto $=3,0 \mathrm{~min}, \mathrm{~T}=25^{\circ} \mathrm{C}$.

Valores médios de três medidas.

Estudo do tempo de saturação do filme captor

O gráfico da Fig. 4 exibe uma rápida variação de frequência nos primeiros minutos, a qual vai diminuindo com o passar do tempo, tendendo a uma região (acima de 20 minutos), em que o sinal analítico tende a uma constância. Isso ocorre, provavelmente, devido à saturação dos sítios ativos do filme, que vai se tornando incapaz de interagir com novas moléculas de amônia que estão chegando ao sensor. 


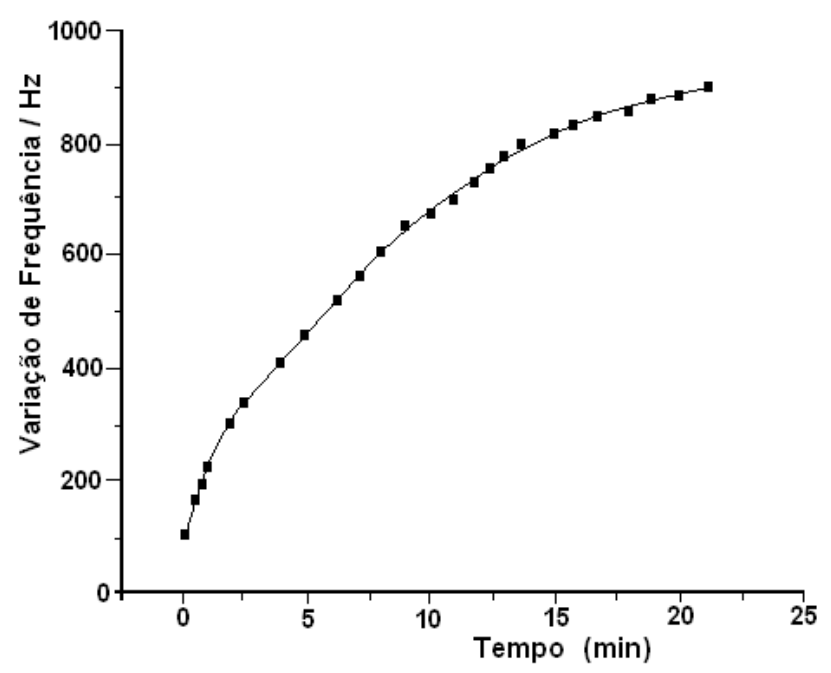

Figura 4. Estudo do tempo de saturação da película captora:

Vazão: $80 \mathrm{~mL} / \mathrm{min}, \mathrm{C}_{\text {amônia }}=6,0 \mathrm{ppm}_{\mathrm{v}}$, massa do filme $133 \mu \mathrm{g}, \mathrm{T}=25^{\circ} \mathrm{C}$.

O tempo de exposição do cristal ao poluente é um parâmetro que pode ser perfeitamente controlado durante a análise. Aumentando-se esse tempo, pode-se aumentar a sensibilidade do sensor piezelétrico. Desta forma, por exemplo, se a concentração de poluente no ar atmosférico estiver abaixo do limite que pode ser detectado, num período de contacto de 1 minuto, pode-se, aumentar este tempo de exposição. Assim, uma pequena modificação em apenas um dos parâmetros é suficiente para se fazer o ajuste da metodologia às novas condições experimentais. Um maior tempo de interação geralmente produz uma maior sensibilidade, tornando possível a detecção de quantidades menores do poluente. Contudo, existe também um limite prático de bom senso, que, neste caso, estaria em torno de 10 minutos (Fig.4). Acima deste valor, as determinações tornam-se mais demoradas e com um ganho mínimo de sensibilidade, não se justificando o emprego de longos tempos de interações.

Estudo da reversibilidade do sensor[38] 
O estudo da reversibilidade (não colocado aqui) mostrou que a película captora utilizada é parcialmente reversível e, portanto, não permitem medidas imediatamente sucessivas com a mesma sensibilidade. Isto significa que a amônia ocupa firmemente os sítios ativos do filme de tal maneira que, ao se passar o gás de arraste puro durante curto tempo para regenerá-lo, uma parte do poluente ainda permanece aderida. Assim, quando se passa o poluente novamente pelo cristal, o sinal analítico diminui, pois o filme já não tem a mesma quantidade de sítios ativos (capacidade) para captar a mesma quantidade do analito. Exemplificando, para o presente filme e tempos de exposição película-analito pequenos (30 s, 1 min), o cristal tem seu sinal regenerado em cerca de $98 \%$. Se utilizado novamente, sua capacidade de sinal ou recuperação cai para 95 $\%$ do sinal anterior. Após um terceiro uso consecutivo, o mesmo cristal teria o seu sinal regenerado em cerca de $90 \%$ e assim sucessivamente, de forma que quanto mais utilizado for o sensor mais difícil e menor será sua \% de recuperação... Nesse mesmo gráfico de regeneração de sinal, em caso de tempos maiores de contacto ( 2 e 4 min), a queda observada nessas percentagens seriabem mais abrupta... Ou seja, após primeiras exposições o filme já ficaria praticamente saturado em seus sítios ativos.

Mesmo não se constatando a completa reversibilidade analítica do "coating", isto não invalida o sensor desenvolvido, pois a preparação e troca de cristais são procedimentos bem rápidos, simples e o filme em estudo é bastante sensível à presença de amônia.

Estudo do efeito da temperatura de trabalho[38]

O desempenho do detector piezelétrico costuma ser afetado pela temperatura de trabalho (célula) em que são realizadas as medidas, sendo assim é um parâmetro que deve ser otimizado na montagem de um novo método analítico. Desta maneira, para a realização deste estudo, colocouse uma serpentina de vidro entre a válvula principal e a célula detectora, estando ambas imersas em banho-maria termostatizado. Assim, no intervalo entre $15-45^{\circ} \mathrm{C}$, anotaram-se as variações de frequência para 
quatro diferentes tempos de leitura $(30 \mathrm{~s}, 60 \mathrm{~s}, 120 \mathrm{~s}$ e $180 \mathrm{~s})$. Este presente estudo também não foi mostrado neste texto.

Observou-se que entre $20^{\circ} \mathrm{C}$ e $35^{\circ} \mathrm{C}$ a temperatura não exerceu qualquer influência sobre o desempenho do sensor piezelétrico, já que o sinal de frequência não variou para cada combinação de temperatura e tempo de exposição. Porém, acima de $35^{\circ} \mathrm{C}$ esta influência passa a ser significativa, provocando uma diminuição da resposta do sensor, a qual pode estar sendo causada por um deslocamento do equilíbrio sorção/dessorção, por volatilização de componente(s) do filme (THEED, ácido glicólico e ácido tânico), alteração na estrutura da película ou por fenômenos combinados.

\section{Construção das curvas analíticas}

Nesta etapa, foram construídas quatro curvas analíticas (Fig.5) correspondentes aos diferentes tempos de exposição entre o cristal e o poluente. Os tempos utilizados foram 30 segundos, 1 minuto, 2 minutos e 3 minutos. Todas as respostas apresentaram uma boa linearidade, na faixa de concentrações estudadas, sendo que as correspondentes aos tempos de exposição de 30 segundos e 1 minuto tiverem um coeficiente de correlação de 0,9994 e 0,9993 respectivamente. Já as correspondentes aos tempos de 2 e 3 minutos apresentaram, respectivamente, os coeficientes de correlação de 0,9982 e 0,9980. Para a obtenção dessas curvas analíticas, todas as medidas foram realizadas nas condições previamente otimizadas. Contudo, apenas o fluxo de trabalho não estava no seu valor ideal devido às limitações do aparelho e sistema montado. Assim, a vazão utilizada foi de $55 \mathrm{~mL} \mathrm{~min}^{-1}$, enquanto a ideal seria de $100 \mathrm{~mL} \mathrm{~min}^{-1}$. 


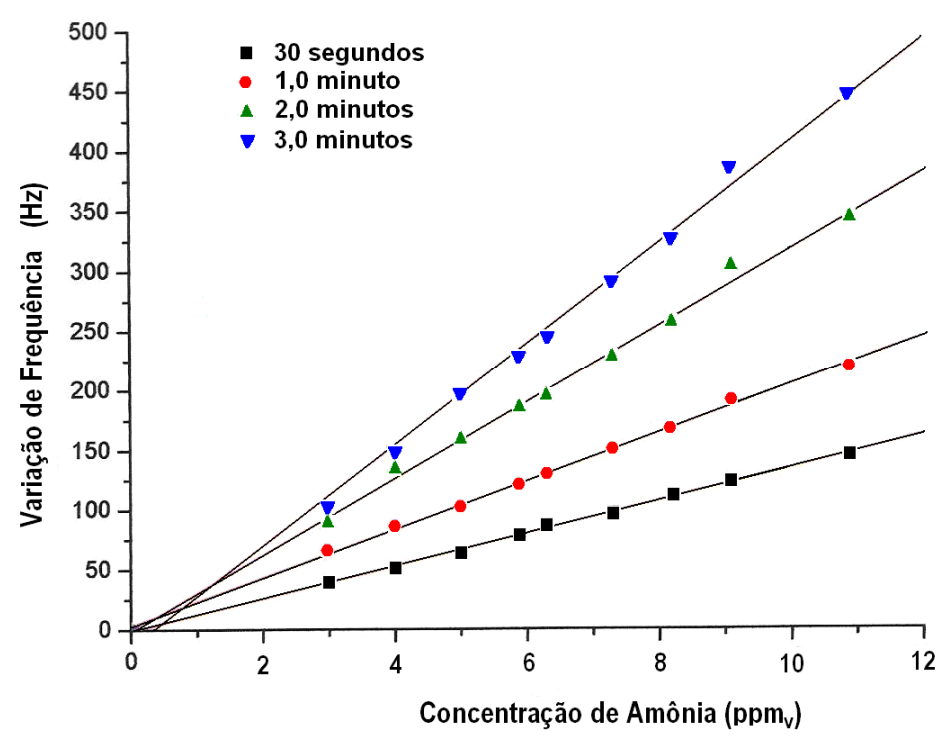

Figura 5. Curvas de calibração para amônia em diferentes tempos de

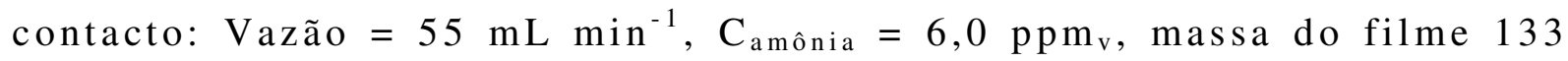
$\mu \mathrm{g}, \mathrm{T}=25^{\circ} \mathrm{C}$.

Comparando os resultados deste trabalho com alguns outros encontrados recentemente na literatura, observa-se que em termos de sensibilidade ele é equivalente ao dispositivo desenvolvido em outro texto preliminar sobre a detecção de amônia, usando este tipo de detector, também realizado em nossos laboratórios. Naquela oportunidade, Teruel [8] utilizou-se de um tubo de permeação e amônia certificado, já envelhecido, que havia sido adquirido no mercado internacional. Naquele trabalho, o melhor filme captor foi uma mistura de Tween 80 com Cloridrato de Piridoxina (1:1), que mostrou resultados semelhantes aos presentes. O sensor desenvolvido por Gomes e colaboradores [9] apresenta uma baixa sensibilidade sendo, além disso, significadamente influenciado pela variação de temperatura. Assim, medidas realizadas entre $20^{\circ} \mathrm{C}$ e $30^{\circ} \mathrm{C}$ fornecem respostas bastante diferentes. Desta forma, aquele sistema deve ter um controle de temperatura bastante eficaz. A calibração do aparelho (curva analítica) 
deve ser feita numa temperatura bem conhecida, e a monitorização do poluente deve ser feita sempre na mesma temperatura, exigindo assim, uma sala climatizada ou outra forma de manter a temperatura de trabalho constante. Por outro lado, o sensor desenvolvido neste trabalho, praticamente não é afetado por pequenas variações de temperatura (entre $20^{\circ} \mathrm{C}$ e $30{ }^{\circ} \mathrm{C}$ ), não exigindo nenhum controle rígido deste parâmetro. Mirmohseni \& Oladegaragoze [10] determinaram recentemente amônia na atmosfera com cristal de quartzo, conseguindo um sinal de frequência de $400 \mathrm{~Hz}$ para uma concentração de $8 \mathrm{mg} \mathrm{L}^{-1}\left(\sim 11.500 \mathrm{ppm}_{\mathrm{v}}\right)$. Como pode ser visto (Fig.5) o sensor desenvolvido neste trabalho mostra-se muito mais sensível, uma vez que, para a mesma variação de frequência (400 $\mathrm{Hz}$ ) pode-se determinar, aproximadamente, 9,0 $\mathrm{ppm}_{\mathrm{v}}\left(6,2 \mathrm{mg} \mathrm{m}^{-3}\right)$.

\section{Estudo de alguns possiveis interferentes}

O sensor foi exposto à passagem de gases comuns encontrados no ar ambiente e também disponíveis em nosso laboratório, tais como: CO (monóxido de carbono), $\mathrm{CO}_{2}$ (dióxido de carbono), $\mathrm{NO}_{2}$ (dióxido de nitrogênio), $\mathrm{H}_{2} \mathrm{~S}$ (sulfeto de hidrogênio) e ar atmosférico (laboratório). Esses gases foram individualmente injetados na linha (sobre o fluxo de amônia), usando em sua preparação o método da diluição em seringa, cuja agulha é inserida no sistema através de um septo adaptado próximo à célula. A seringa utilizada tinha capacidade de $50 \mathrm{~mL}$ e os gases interferentes foram obtidas a partir de cilindros pressurizados contendo as substâncias puras ou diluídas a $10 \%$ (v/v) em nitrogênio. A tabela 3 apresenta o resultado deste estudo. 
Tabela 3. Estudo de alguns possíveis interferentes na detecção de amônia

Possíveis Interferentes Concentração $\left(\mathbf{p p m}_{\mathrm{v}}\right) \quad \Delta \mathbf{F}(\mathbf{H z})$

Tempo de Contacto

\begin{tabular}{llllll}
\cline { 3 - 5 } & & $\mathbf{3 0} \mathbf{~}$ & $\mathbf{1 , 0} \mathbf{m i n}$ & $\mathbf{2 , 0} \mathbf{~ m i n}$ & $\mathbf{3 , 0} \mathbf{~ m i n}$ \\
\hline \hline Ar atmosférico & Sem diluição & 0 & 0 & 0 & 0 \\
$\mathrm{CO}$ & 100 & 0 & 0 & 0 & 0 \\
$\mathrm{CO}_{2}$ & 50 & 0 & 0 & 0 & 0 \\
$\mathrm{H}_{2} \mathrm{~S}$ & 100 & 0 & 0 & 0 & 0 \\
$\mathrm{NO}_{2}$ & 1 & 5 & 12 & 43 & 47 \\
\hline
\end{tabular}

Dos gases estudados, apenas o $\mathrm{NO}_{2}$ apresentou certa interferência, mesmo para concentrações baixas. Desta forma, esta substância deve estar ausente do ar investigado ou deve-se inserir na linha algum estágio (coluna) específico para retenção do $\mathrm{NO}_{2}$, como normalmente se procede para evitar interferências específicas.

Estudo da repetibilidade do sensor piezelétrico

Neste estudo foram realizadas catorze medidas utilizando as mesmas condições otimizadas, num mesmo dia, mesma concentração de amônia $\left(6,0 \mathrm{ppm}_{\mathrm{v}}\right)$, mesmo sistema, aparelhos e analista. Os resultados estatísticos finais, para os diferentes tempos de exposição, acham-se resumidos na tabela 4. 
Tabela 4. Valores médios e limites de confiança

\begin{tabular}{lllll}
\hline Tempo(s) & $\boldsymbol{\Delta} \mathbf{F}^{\mathbf{a}}(\mathbf{H z})$ & Desvio $(\boldsymbol{\%})$ & $\begin{array}{l}\text { Intervalo } \\
\text { confianca }\end{array}$ & de \\
& & & $\mathbf{5 0 \%}$ & $\mathbf{9 0 \%}$ \\
\hline 30 & $280 \pm 5$ & 2,4 & $280 \pm 1$ & $280 \pm 3$ \\
60 & $318 \pm 6$ & 1,9 & $318 \pm 1$ & $318 \pm 3$ \\
120 & $444 \pm 10$ & 2,3 & $444 \pm 2$ & $444 \pm 5$ \\
180 & $540 \pm 13$ & 2,4 & $540 \pm 3$ & $540 \pm 6$ \\
\hline
\end{tabular}

${ }^{a}$ Média de 14 medidas sucessivas.

\section{Conclusões}

O filme (coating) mais promissor encontrado foi uma mistura $2: 1$ (v/v) de (A) solução aquosa comercial de ácido glicólico $(70 \% \mathrm{~m} / \mathrm{m})$ em THEED (3:4 v/v) com uma solução saturada (B) de ácido tânico em acetona, sendo de $133 \mu \mathrm{g}$ a espessura ideal do revestimento, correspondente a uma variação de frequência de aproximadamente $67 \mathrm{kHz}$. A melhor vazão de trabalho está na faixa de $80-100 \mathrm{~mL} \mathrm{~min}^{-1}$ e temperaturas entre $15-35^{\circ} \mathrm{C}$ não apresentaram efeitos significativos sobre a sensibilidade das medidas. O sensor apresentou sinal de frequência linear no intervalo de concentração estudado de $2-11 \mathrm{ppm}_{\mathrm{v}}\left(1,4\right.$ a $\left.7,7 \mathrm{mg} \mathrm{m}^{-3}\right)$. As respectivas equações de reta e suas sensibilidades $\left(\mathrm{Hz} / \mathrm{ppm}_{\mathrm{v}}\right)$ são: $\mathrm{y}=-1,27+13,52$. $\mathrm{x}$ ; $\mathrm{y}=3,35+20,00 . \mathrm{x} ; \mathrm{y}=-1,43+31,76 . \mathrm{x}$ e $\mathrm{y}=-14,22+42,03 . \mathrm{x}$. Dentre os possíveis interferentes estudados, apenas o $\mathrm{NO}_{2}$ afetou as medidas, devendo estar ausente. Com relação a repetibilidade, o método pode ser considerado satisfatório porque apresentou baixo desvio de valores nos intervalos de confiança estudados (50 $90 \%)$. A relativa demora da calibração do tubo de permeação artesanal e a reversibilidade parcial do filme foram plenamente compensadas pelo curto tempo e facilidade do preparo dos cristais, das medidas, alta sensibilidade do sensor, resposta rápida e baixo custo de aparelhagem e reagentes. 


\section{Agradecimentos}

Os autores agradecem ao CNPq e à FAPESP pelos auxílios concedidos e, também, ao Prof. Dr. Arnaldo A. Cardoso (IQ-UNESP), pelo empréstimo de um tubo de permeação artesanal.

\section{Referências Bibliográficas}

[1] - FEliX, E. P.; CARdosO, A. A. - Amônia (NH3) atmosférica: fontes, transformação, sorvedouros e métodos de análise. Quím.Nova $27(1)(2004) 123$.

[2] - World Health ORganization (WhO) - Ammonia. In: The Environmental Health Criteria Series, Geneva, WHO-IPCS, 1986 /Environmental Health Criteria 54/.

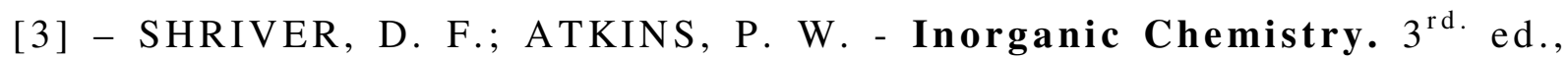
Oxford, Oxford University Press, 1999, 765p.

[4] - CHAGAS, A. P. - A Síntese de amônia: alguns aspectos históricos. Quím.Nova 30(1) (2007) 240.

[5] - FRITSCHE, U.; GERNERT, M. - Gas-sensitive electrode applied to the continous measurement of atmospheric ammonia, Anal. Chim. Acta 224 (1991) 179.

[6] - LUO, Y.Y.; Alothman, R.; Christian, G.D.; RUZiCKA, J. Flow sequential injection determination of gaseous ammonia with a glass diffusion denuder, Talanta 42 (1995) 1545.

[7] - FRENZEL, W.; GRIMM, E.; GRUETZMACHER, G. - Evaluation of a diffusive sampling method for the determination of atmospheric ammonia, J.Anal.Chem. 351 (1995) 19.

[8] - TERUEL, F.S. - Estudo sobre a determinação de amônia e tolueno diisocianato utilizando microbalança piezoelétrica, Universidade de São Paulo. Departamento de Química da FFCLRP. Ribeirão Preto/SP, 1999 /Dissertação de Mestrado/. 
[9] - GOMES, M.T.S.R.; NOGUEIRA, P.S.T.; OLIVEIRA, J.A.B.P. Quantification of $\mathrm{CO}_{2}, \mathrm{SO}_{2}, \mathrm{NH}_{3}$ and $\mathrm{H}_{2} \mathrm{~S}$ with a single coated piezoelectric quartz crystal, Sens. Actuators B 68 (2000) 218 .

[10] - Mirmohseni, A.; Oladegaragoze, A. - Construction of a sensor for determination of ammonia and aliphatic amines using polyvinylpyrolidone coated quartz crystal microbalance. Sens. Actuators B 89 (2003) 164.

[11] - HOller, F.J.; SKOOG, D.A.; CROUCH, S.R. - Princípios de análise instrumental, $6^{a}$.ed. (trad. Célio Pasquini e outros), Porto Alegre, Bookman, 2009, p.23-4.

[12] - SAUERBREY, G. - Verwendung von schwingquarzen zur wägung dünner schichten und zur mikrowägung, Z. Phys.155 (1959) 206.

[13] - ThOMPSON, M.; KIPling, A.L.; DUNCAN-HEWITT, W.C.; RAJAKOVIC, L.V.; CAVIC-VLASAK, B.A. - Analyst 116 (1991) 881.

[14] - ANDRADE, J.F.; FAtibello-Filho, O.; OliveirA NETO, G.; GUilbault, G.G. - Aplicações analíticas dos cristais piezelétricos, Quím. Nova 14(4) (1991) 272.

[15] - KING, W.H., Jr. - Piezoelectric sorption detector. Anal.Chem. 36(9) (1964) 1735 .

[16] - KING, W.H., Jr. - Res. / Develop. 20 (1969) 28.

[17] - KING, W.H., Jr. - Applications of the quartz crystal resonator. In: Vacuum Microbalance Techniques (Czanderna, A.W., ed.), New York, Plenum Press, p. 183-99, 1971, v.8.

[18] - O’Sullivan, C.K.; Guilbault, G.G. - Commercial quartz crystal microbalances - theory and applications. Biosens. Bioelectron. 14 (1999) 663.

[19] - KARMARKAR, K.H; Guilbault, G.G. - Anal. Chim. Acta 75 (1975) 111 .

[20] - WebBer, L.M.; GuIlbAult, G.G. - Anal. Chem. 48 (1976) 2244.

[21] - SUlEIMAN, A.A.; HAHN, E.C.; GUIlBAUlT, G.G.; CAVANAUGH, J.R. - Anal. Lett. 17 (1984) 2205. 
[22] - ANDRADE, J.F.; SUlEIMAN, A.A.; GUIlbAUlT, G.G. Anal.Chim.Acta 217 (1989) 187.

[23] - GUilbault, G.G.; LOPEZ-ROMAN, A. - Environ. Lett. 2 (1971) 35 .

[24] - LOPEZ-ROMAN, A.; GUilbAult, G.G. - Anal.Lett. 15 (1972) 225 .

[25] - FAtibello-FIlHo, O.; ANDRADE, J.F.; SUlEIMAN, A.A.; GUILBAULT, G.G. - Anal.Chem. 61 (1989) 746.

[26] - GUilbaulT, G.G. - Anal.Chem. 55 (1983) 1682.

[27] - ANDRADE, J.F.; FATIBELLO-FILHO, O.; SULEIMAN, A.A.; GUILBAULT, G.G. - Anal.Lett. 22 (1989) 2601.

[28] - GUILBAUlT, G.G. - Anal.Chim.Acta 39 (1967) 260.

[29] - Guilbault, G.G.; TOMita, Y.; KOlesAR, E.S. - A Coated Piezoelectric Crystal to Detect Chemical Warfare Agents in Aircraft, US Air Force Report, SAM-TR-80-21, July 1980.

[30] - DING, B., YAMAZAKI, M., SHIRATORI, S. - Electrospun fibrous polyacrylic acid membrane-based gas sensors. Sens. Actuators B. 106 (2005) 477.

[31] - GeORgieVA, V., SPASSOV, L., DONKOV, N., PETKOV, P., ATANASSOV, M., - Detection of $\mathbf{N H}_{3}$ by Quartz Crystal Microbalance Coated with Ta $\mathbf{a}_{2} \mathbf{O}_{5}$. Plasma Process Polym. 3 (2006) 209.

[32] - WANG, X., ZHANG, J., ZHU, Z., - Ammonia sensing characteristics of ZnO nanowires studied by quartz crystal microbalance. Appl. Surf. Sci. 252 (2006) 2404.

[33] - NELSON, G.O. - Controlled test atmospheres: principles and techniques, Ann Arbor, Ann Harbor Science Publisher, 1971, 247p.

[34] - Wight, G.D. - Fundamentals of Air Sampling, Boca Raton, New York, Lewis Publishers, 1994, 254p.

[35] - TECKEntRuP, A., KLOCKOW, D. - Preparation of refillable permeation tubes. Anal.Chem. 50(12) (1978) 1728. 
[36] - CROSBY, D.G. - Environmental toxicology and chemistry. New York: Oxford University Press, 1998, 336p.

[37] - O'KEEFFE, A.E.; ORTMAN, G.C. - Primary standards for trace gas analysis. Anal.Chem. 38 (1966) 760.

[38] - CASTRO, J.R.M. - Estudo sobre a determinação de benzeno e amônia no ar, utilizando sensor piezelétrico de quartzo, Universidade de São Paulo. Departamento de Química da FFCLRP. Ribeirão Preto/SP, 2005 /Dissertação de Mestrado/.

Title: Determination of ammonia in air using a coated quartz crystal sensor

Abstract:

Ammonia was detected and determined by a piezoelectric quartz crystal sensor coated with a 2:1 (v/v) mixture of (A) commercial aqueous solution of glycolic acid $(70 \%$ w/w $)$ combined with tetrakis(hydroxyethyl) ethylenediamine - THEED $(3: 4 \mathrm{v} / \mathrm{v})$ and a saturated solution of (B) tannic acid in acetone. A large quantity of promising substances and their mixtures, under different proportions, were initially studied as possible films. The effects of flow rate, cell temperature, and the amount of coating were investigated, to establish the best experimental conditions. Studies on repeatability, sampling times and some possible interfering gases were performed. The analytical curves are linear over the concentration range (2.0-11 $\mathrm{ppm}_{\mathrm{v}}$ or 1.4-7.7 $\mathrm{mg} \mathrm{m}^{3-}$ ) for four different sampling times $(0.5 ; 1 ; 2$ and $3 \mathrm{~min})$, with good linearity correlation (r) varying between 0.9994 and 0.9980 and respective sensitivities ranging from 13.5 to $42.0 \mathrm{~Hz} / \mathrm{ppm}_{\mathrm{v}}$.

Keywords: ammonia, piezoelectric sensor (QCM), glycolic-tannic acidsTHEED coating. 